\title{
ESTUDO DA POTENCIALIDADE DOS PROCESSOS \\ REDUTIVOS NA DEGRADAÇÃO DE CORANTES ORIUNDOS DA INDÚSTRIA TÊXTIL
}

\author{
STUDY OF THE POTENTIAL OF REDUCTIVE \\ PROCESSES IN THE DEGRADATION OF DYES FROM \\ THE TEXTILE INDUSTRY
}

\author{
Ana Paula Peron \\ Vanessa Maria Ribas Ransolin \\ Elaine Regina Lopes Tiburtius*
}

\begin{abstract}
RESUMO
A descarga de efluentes das indústrias têxteis causam considerável poluição estética e riscos à saúde, principalmente devido à alta carga orgânica, forte coloração e potencial carcinogênico e mutagênico dos corantes sintéticos. Os processos convencionais de remediação não são eficientes na degradação desses poluentes. Assim, surgem novas alternativas para o tratamento destes efluentes. $\mathrm{O}$ presente estudo tem como objetivo avaliar a potencialidade do processo redutivo, utilizando ferro de valência zero e lã de aço na degradação do corante preto reativo 5. Os dois processos analisados neste trabalho foram bastante relevantes para a degradação do corante. No entanto, a maior eficiência na remediação foi obtida quando foi utilizada lã de aço com $90 \%$ de degradação em 15 minutos de tratamento.
\end{abstract}

Palavras-chaves: Degradação. Processos redutivos. Corantes têxteis. Ferro zero.

\begin{abstract}
The discharge of effluents from the textile industry causes considerable visual pollution and health risks, mainly due to the high organic load, intense color and the carcinogenic and mutagenic potential of synthetic dyes. Conventional treatment processes have not been efficient in degrading these pollutants. Thus, new alternatives for such treatment of these effluents are arising. This study evaluated the potential of the reductive process using zero-valent iron and iron wool for the degradation of reactive black 5 dye. Both the processes studied in this work were very efficient in the degradation of the dye. However, the highest efficiency was obtained in the treatment using iron wool, which resulted in $90 \%$ degradation of $90 \%$ in 15 minutes of treatment.
\end{abstract}

Keywords: Degradation. Reductive process. Textile dyes. Zero-valent iron.

\footnotetext{
"Departamento de Química, Universidade Estadual de Ponta Grossa (UEPG). E-mail: <erltiburtius@uepg.br>
} 


\section{Introdução}

A água é um dos recursos naturais mais importantes do planeta, sendo fundamental em inúmeras atividades, como por exemplo, em processos produtivos industriais. Dentro desse contexto, destacam-se as indústrias têxteis, devido ao abundante uso de água, e, consequentemente, à geração significativa de efluentes que provocam impactos ambientais, principalmente pela toxidade de seus compostos e seu aspecto estético. Isto é, por serem altamente coloridos, devido à presença de corantes que não se fixaram durante o processo de tingimento, e se liberados sem o devido tratamento, podem provocar a morte da fauna e flora aquáticas, bem como interferir em processos de fotossíntese em corpos d'água atingidos. (SHANG et al., 2011; CHEN et al., 2011). Além desse fato, estudos indicam que algumas classes de corantes e seus subprodutos podem ser carcinogênicos e/ou mutagênicos. (DEVI et al., 2009).

Os métodos mais utilizados para o tratamento desse tipo de efluente são os biológicos, não efetivos na remoção da cor e geram grandes quantidades de lodos. Devido a tais implicações, é de suma importância o conhecimento de métodos mais eficazes para tratamento de efluentes têxteis. (ANTONIALI et al., 2009). Um exemplo promissor, e que tem se mostrado bastante eficiente para a remediação desse tipo de efluentes, é o que utiliza o ferro de valência zero (GUARATINI et al., 2000). Os tratamentos por meio de processos oxidativos avançados, conhecidos como POA, caracterizam-se pela geração de espécies fortemente oxidantes, principalmente radicais hidroxila, capazes de promover rapidamente a degradação de vários compostos poluentes. (CHAN et al., 2012; OLLER et al., 2011; GUIMARÃES et al., 2009; PEREIRA et al., 2005).

Apesar de os POA serem uma alternativa de tratamento bastante estudada, a geração de radicais hidroxila é um processo de custo relativamente alto, e apresenta uma série de dificuldades para sua implementação em grande escala. Além disso, alguns compostos com centros deficientes em elétrons, como por exemplo, os halogenados e nitrogenados, reagem muito lentamente aos radicais hidroxila. Diante disso, o ferro metálico se mostra uma ferramenta promissora no tratamento dos efluentes, uma vez que é um excelente agente redutor $\left(\mathrm{E}^{0} \mathrm{Fe}^{0} / \mathrm{Fe}^{2+}\right.$ $-0,440 \mathrm{~V})$, eficiente na degradação de compostos re- calcitrantes, de fácil obtenção, baixo custo e baixa toxicidade. (WANG et al., 2010; SHU et al., 2010).

O presente trabalho teve como objetivo principal a investigação da capacidade do processo redutivo, utilizando ferro em pó e lã de aço na degradação do corante preto reativo 5 , um azo-corante representativo da indústria têxtil.

\section{Materiais e Métodos}

Os principais reagentes utilizados foram soluções aquosas de $25 \mathrm{mg} \mathrm{L}^{-1}$ do corante preto reativo 5 (Aldrich 55\%), ferro metálico em pó (Vetec), sulfato ferroso amoniacal (Synth), ácidos e bases, e lã de aço (Bombril®). Os estudos foram conduzidos em escala de bancada e sob agitação.

A determinação de ferro total foi avaliada utilizando o método colorimétrico fundamentado na reação de complexação entre o $\mathrm{Fe}^{2+} \mathrm{e}$ o-fenatrolina. A eficiência do processo de degradação do corante foi avaliada por espectroscopia UV-vis, utilizando um espectrofotômetro Shimadzu (Multispec - 1501). Já as determinações de carbono orgânico total, foram realizadas em um analisador próprio, o Shimadzu TOC-VCPC da Universidade Federal do Paraná (UFPR). O método é fundamentado na oxidação catalítica de compostos orgânicos a elevadas temperaturas (tubo de combustão a $680^{\circ} \mathrm{C}$ contendo platina suportada em alumina) e detecção de $\mathrm{CO}_{2}$ por espectroscopia no infravermelho. Por fim, As variáveis importantes do processo redutivo, tais como massa de ferro e $\mathrm{pH}$, foram avaliadas utilizando planejamento fatorial de experimentos.

\section{Resultados e Discussão}

Primeiramente, avaliou-se a potencialidade do processo redutivo com o uso do ferro em pó na descoloração de um azo-corante, corante sintético representativo da indústria têxtil (LIU et al., 2011). Para tal, utilizamos um planejamento fatorial bastante simples, em que todos os fatores foram estudados em dois níveis. Nesse estudo, as variáveis massa de ferro em pó e pH foram avaliadas com base em um planejamento fatorial de $2^{2}$, a fim de obter as melhores condições para a degradação do corante preto reativo 5. Os resultados obtidos são apresentados na Tabela 1. 
Tabela 1 - Planejamento $2^{2}$ para otimização do processo redutivo via ferro em pó

\begin{tabular}{c|c|c|c}
\hline Ensaio & $\mathrm{pH}$ & Massa (g) & Degradação (\%) \\
\hline 1 & 4 & 2 & $83 \pm 3$ \\
\hline 2 & 6 & 2 & $74 \pm 3$ \\
\hline 3 & 4 & 6 & $91 \pm 3$ \\
\hline 4 & 6 & 6 & $90 \pm 3$ \\
\hline
\end{tabular}

Com base nos resultados, os efeitos de primeira ordem para o $\mathrm{pH}$ e para a massa de ferro utilizada foram calculados. Para o $\mathrm{pH}$, o valor encontrado foi de $-5,2 \%$, o que significa que, ao elevar-se o $\mathrm{pH}$ de 4 para 6 , a eficiência na degradação do corante diminui $5,2 \%$ e, consequentemente, não é vantajoso que a reação ocorra em $\mathrm{pH}$ maiores, como o $\mathrm{pH}$ 6, por exemplo. Dessa forma, podemos concluir que o $\mathrm{pH}$ exerce um efeito significativo no processo de remoção da cor. Além disso, é importante destacar que o efeito discreto da variável $\mathrm{pH}$ para eficiência da degradação está de acordo com a literatura. (SOUZA, 2006) Com o intuito de verificar diferenças existentes entre o processo redutivo, mediado por ferro metálico e oxidação assistida pelo processo Fenton, foi realizado um estudo preliminar via planejamento fatorial. Os resultados demonstraram que o efeito do $\mathrm{pH}$ é significativo, bem como que melhores resultados de descoloração podem ser alcançados quando o sistema opera em $\mathrm{pH}$ mais baixo. Ainda, Hipólito (2008), em estudos de degradação do corante azul reativo 4 via ferro zero também observou que a taxa de descoloração aumenta com a diminuição do $\mathrm{pH}$.

Por outro lado, o valor calculado do efeito de primeira ordem para a massa de ferro foi igual a $12,4 \%$, o que indica que, quando aumentamos a massa de $2 \mathrm{~g}$ para $6 \mathrm{~g}$, obtém-se um aumento na eficiência de degradação de aproximadamente $12 \%$. O aumento na taxa de remoção da cor com o aumento da massa de ferro já era esperado, principalmente, em razão da maior disponibilidade de sítios reativos. Além disso, é possível verificar que, nessas condições, em maior massa de ferro, a influência do pH é pouco significativa. Portanto, verifica-se que o efeito do $\mathrm{pH}$ depende da concentração de ferro, ou seja, há uma interação entre estas duas variáveis.

Realizou-se então, por meio desses estudos preliminares, a avaliação da capacidade de degradação, utilizando a maior massa de ferro e pH na- tural do corante $(\mathrm{pH}=6,3)$ visando a eliminação de etapas para correção de $\mathrm{pH}$. O controle da eficiência do processo redutivo, quando usado o ferro em pó, como proposto neste trabalho, foi avaliado por espectroscopia UV-vis, coletando alíquotas a cada 15 minutos e monitorando a redução do comprimento de onda de máxima absorbância do corante $(\lambda=$ $597 \mathrm{~nm}$ ). Os resultados são mostrados na Figura 1, em que se pode observar elevada capacidade do processo redutivo na degradação do corante, ou seja, índices de cerca de $80 \%$ da remoção da cor foram alcançados em apenas 45 minutos de reação.

Figura 1 - Estudo de degradação do corante preto reativo 5 via processo redutivo utilizando ferro em pó em pH 6,3.

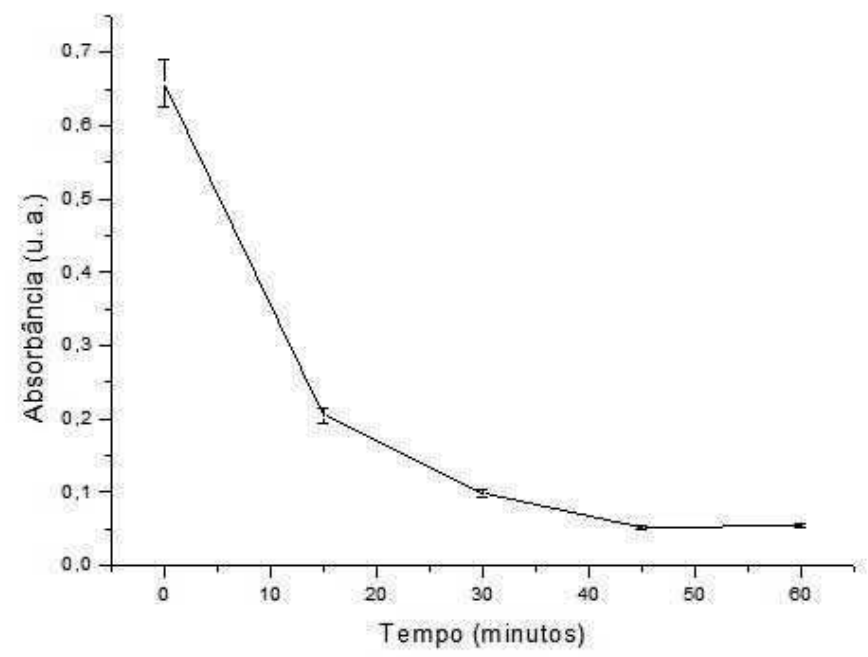

Em particular, para o sistema redutivo, quando utilizado ferro em pó, foi possível avaliar também a capacidade do sistema na remoção do carbono orgânico total. A evolução do teor de carbono orgânico é um parâmetro importante, pois indica o processo de mineralização. Sendo assim, pode-se investigar a capacidade do sistema em relação à mineralização do azo-corante utilizado neste trabalho, corante preto reativo 5 , monitorando a variação do carbono orgânico dissolvido (COD) durante a reação de degradação. Os resultados obtidos encontram-se na Figura 2 e indicam uma remoção máxima de aproximadamente $50 \%$ em tempos de reação de 60 minutos. Isso demonstra que o sistema é bastante eficiente na quebra de grupos cromóforos presentes na estrutura do corante. No entanto, nas condições estudadas, o processo redutivo não promoveu a total 
conversão das moléculas dos corantes em compostos mais simples, tais como $\mathrm{CO}_{2}$ e $\mathrm{H}_{2} \mathrm{O}$.

Figura 2 - Variação do carbono orgânico dissolvido durante a cinética de degradação do corante preto 5 via processo redutivo utilizando ferro em pó em $\mathrm{pH}$ 6,3 .

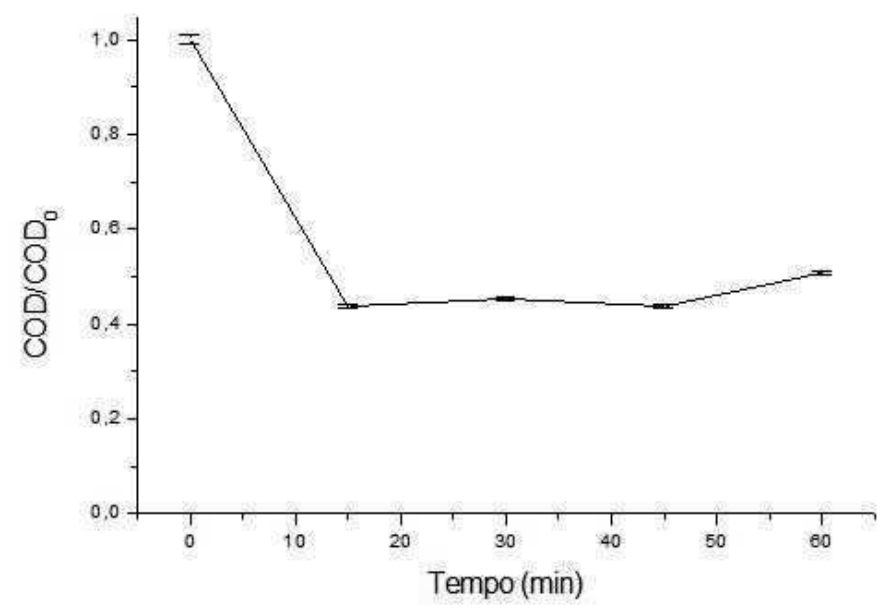

A próxima etapa foi avaliar a capacidade do sistema redutivo na degradação do corante utilizando lã de aço. Foram realizados estudos preliminares por meio do planejamento fatorial de experimentos para avaliar tipo e massa de ferro, mantendo o $\mathrm{pH}$ natural do corante (condições previamente avaliadas com ferro em pó). Os resultados são mostrados na Tabela 2, e se pode observar que não há diferença significativa entre o uso do ferro em pó e a lã de aço quando comparados ao desvio típico (5\%). É importante destacar que, durante o processo redutivo, íons ferrosos são liberados e a possibilidade da utilização de uma massa menor no caso da lã de aço é bastante interessante. Além disso, o uso da lã de aço pode ser uma excelente fonte de ferro em sistemas contínuos de degradação tendo em vista o tratamento de um maior volume de efluente.

Tabela 2 - Resultados obtidos do planejamento fatorial $2^{2}$ utilizando-se lã de aço

\begin{tabular}{c|c|c|c}
\hline Ensaio & Tipo de Ferro & Massa $(\mathrm{g})$ & Degradação (\%) \\
\hline 1 & Pó & 2 & $96 \pm 5$ \\
\hline 2 & Lã de aço & 2 & $93 \pm 5$ \\
\hline 3 & Pó & 6 & $85 \pm 5$ \\
\hline 4 & Lã de aço & 6 & $90 \pm 5$ \\
\hline
\end{tabular}

Após os estudos preliminares das variáveis importantes para o sistema de degradação, realizou-se um estudo cinético de 1 hora para verificar a eficiência do processo redutivo, utilizando-se de uma menor quantidade de lã de aço e pH natural do corante. Os resultados são mostrados na Figura 3 , que monitora o comprimento de onda de máxima absorbância do corante. Pode-se observar que o sistema apresenta maior capacidade de remoção da cor quando comparado ao sistema que usa ferro em pó, isto é, quase $90 \%$ de degradação em aproximadamente em 15 minutos de reação. Infelizmente, a elevada velocidade do processo de degradação nas nossas condições experimentais impede a obtenção de um número suficiente de dados, monitorando o desaparecimento dos substratos em estudo, o que inviabiliza a realização de estudos cinéticos de maior confiabilidade. No entanto, podemos destacar que, quando comparamos os dois sistemas, é possível propor que a velocidade de reação da remoção do corante seja significativamente maior utilizando lã de aço como fonte de ferro de valência zero.

Figura 3 - Estudo da degradação do corante preto reativo 5 utilizando lã de aço e pH natural do corante $(\mathrm{pH}=6,3)$.

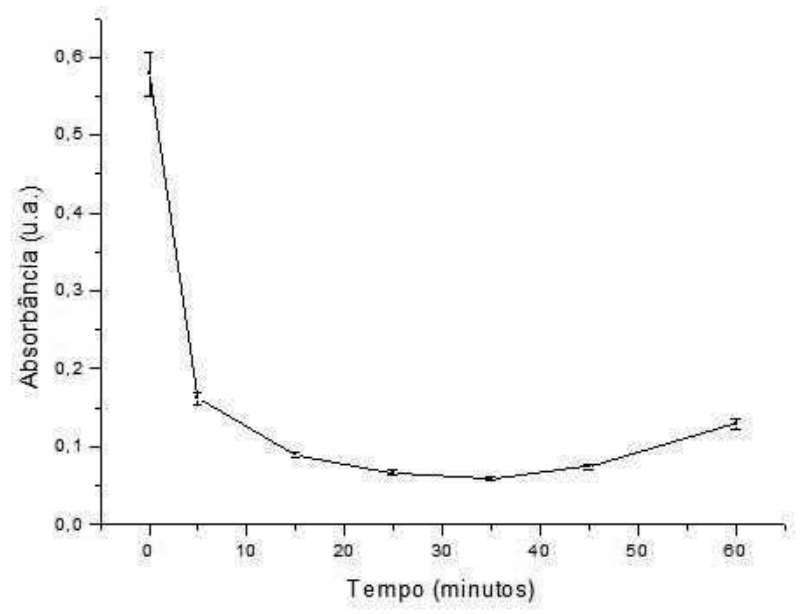

De acordo com a resolução 397/2008 do CONAMA, a liberação de ferro total não pode ser superior a $15 \mathrm{mg} \mathrm{L}^{-1}$. Sendo assim, a quantidade de ferro liberado durante o processo de remoção do corante é um fator relevante quando consideramos a legislação vigente. A quantidade de íons férricos e ferrosos contidos na solução do corante foi monitorada durante o tratamento. Na Figura 4, 
podemos observar que a liberação de ferro total durante o processo de degradação do corante não ultrapassou $5 \mathrm{mg} \mathrm{L}^{-1}$, resultado bastante relevante uma vez que, nessas condições, o efluente encontrase dentro dos limites impostos pela legislação, e, portanto, evitam-se ações corretivas para eliminação de ferro total e, consequentemente, diminuem os custos relacionados à remoção de lodo gerado durante o tratamento do corante.

Podemos assumir, de acordo com os resultados aqui apresentados, que a lã de aço pode ser utilizada como fonte de ferro metálico em sistemas redutivos, para a degradação de corantes com bastante eficiência. Embora não tenha sido possível avaliar quais dos dois processos mencionados proporcionam a máxima mineralização, os resultados sugerem uma boa potencialidade do processo redutivo quando a lã de aço é utilizada na aplicação de sistemas contínuos em escala maior para remoção da cor de corantes típicos da indústria têxtil, como já comentado anteriormente.

Figura 4 - Determinação de Ferro Total

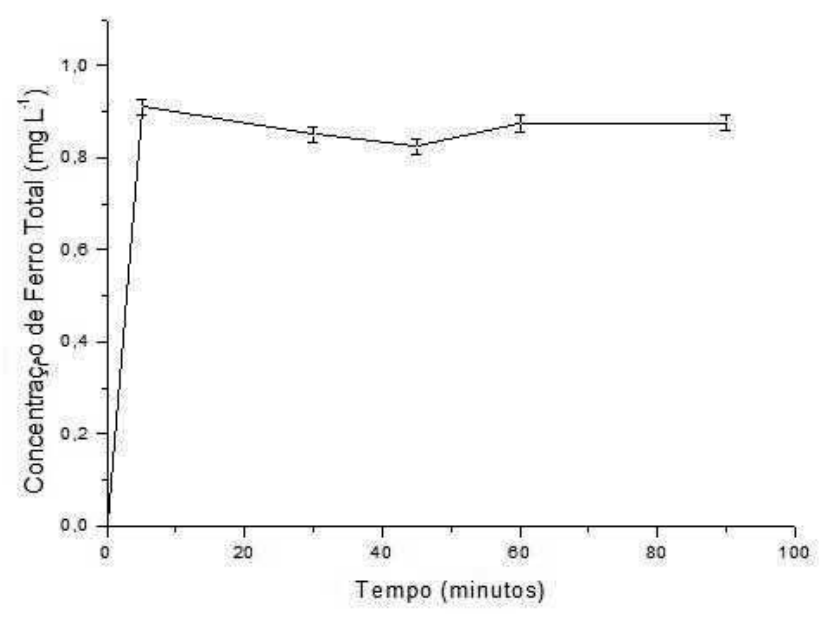

\section{Conclusões}

Pode-se concluir que os resultados obtidos até o presente momento foram bastante promissores. $\mathrm{O}$ ferro de valência zero se mostrou muito eficiente em relação à degradação do corante pelos dois sistemas, utilizando ferro em pó $(80 \%$ de degradação em tempos de $45 \mathrm{~min}$ ) ou lã de aço ( $90 \%$ de degradação em tempos de $15 \mathrm{~min}$ ). No entanto, o sistema no qual a lã de aço foi empregada como fonte de ferro de valência zero se apresentou mais promissor, tendo em vista a baixa liberação de íons férricos e ferrosos, fator importante considerando os padrões impostos pela legislação vigente quanto ao descarte de efluentes, Além de destacar-se pela simplicidade e baixo custo dos materiais utilizados.

\section{Referências}

ANTONIALI, N.; OLIVEIRA, G. L.; VIDAL, C. M. de S. Caracterização e propostas de tratamento para efluentes de indústrias têxteis. VII Semana de Engenharia Ambiental, Junho de 2009, Irati. Anais...

CHEN, B.; XIKUI, W.; CHEN, W.; WENGIANG, J.; SHUPING, L. Degradation of azo dye direct sky blue 5B by sonication combined with zero-valent iron. Ultrasonics Sonochemistry, v.18, p.1091-1096, 2011.

CHAN, P.Y.; EL-DIN, G. M.; BOLTON, R. J. A solar driven UV/Chlorine advanced oxidation process. Water Research, v.46, n.17, p.5672-5682, 2012.

EPOLITO, J. W.; YANG, H.; BOTTOMLEY, A. L.; PAVLOSTATHIS, G. S. Kinetics of zero-valent iron reductive transformation of the anthraquinone dye reactive blue 4. Journal of Hazardous Materials, v.160, p.594$600,2008$.

DEVI, G. L.; GIRISH, K. S.; MOHAN, K. R.; MUNIKRISHNAPPA, C. Photo degradation of methyl orange an azo dye by advanced Fenton process using zero valent metallic iron: influence of various reaction parameters and its degradation mechanism. Journal of Hazardous Materials, v. 164, n. 2-3, p. 459-467, 2009.

GUARATINI, C. C. I.; ZANONI, M. V. B. Corantes têxteis, Química Nova, v.23, p.71-78, 2000.

GUIMARÃES, J. R.; MANIERO, G. M.; ARAÚJO, N. R. A comparative study on the degradation of RB-19 dye in na áqueos médium by advanced oxidation processes. Journal of Environmental Management, v. 110, p. 33-39, 2012.

LIU, Y.; YAOBIN, Z.; XIE, Q.; JINGXIN, Z.; HUIMIN, Z.; CHEN, S. Effects of an electric field and zero valent iron on anaerobic treatment of azo dye wastewater and microbial community structures. Bioresource Technology, v.102, n.3, p. 2578-2584, 2011.

OLLER, I.; MALATO, S.; SÁNCHEZ-PÉREZ, J. A. Combination of advanced Oxidation processes and biological treatments for wastewater decontamination: a review. Science of The Total Environment, v. 409, n. 20, p.4141-4166, 2009.

PEREIRA, W. S.; FREIRE, S. R. Ferro Zero: uma nova abordagem para o tratamento de águas contaminadas com compostos orgânicos poluentes. Química Nova, São Paulo, v. 28, n.1, p. 130-136, Fevereiro, 2005. 
Resolução CONAMA. n. 397, 3 de Abril de 2008. Ministério do Meio Ambiente, 2008. Disponível em: $<$ http://www.ufpa.br/numa/pos_graduacao/PROFIMA/ gestao_sustentavel_municipios/bacias_hidrograficas_ planejamento/CONAMA_RES_CONS_2005_357.pdf >. Acesso em: 12 dez 2012.

SHU, H- Y.; MING-CHIN C.; CHI-CHUN C. E PO-EN C. Using resin supported nano zero-valent iron particles for decoloration of acid blue 113 azo dye solution. Journal of Hazardous Materials, v.184, n.1-3, p.499-505, 2010.

SOUZA, C. D. L.Degradação de corantes reativos e remediação de efluentes têxteis por processo avançados envolvendo ferro metálico. 2006, 100f. Dissertação (Mestrado em Química). Universidade Federal do Paraná, Curitiba, 2006.

WANG, K. W.; CHIOU-LIANG, L.; MING-CHI, W.; HSIUHAO, L.; HENG-CHING, L.; CHIH-HUA, C.; YUNGTAI, F.; SHIH-HSIEN, C.. Effects of dissolved oxygen on dye removal by zero-valent iron. Journal of Hazardous Materials, v.182, n.1-3, p.886-895, 2010.

Recebido em 26/02/2013

Aceito em 17/04/2013 